\title{
Comparison of tumors with HER2 overexpression versus $H E R 2$ amplification in HER2-positive breast cancer patients
}

\author{
Yoshiya Horimoto ${ }^{1,2^{*}} \mathbb{D}$, Yumiko Ishizuka ${ }^{1}$, Yuko Ueki ${ }^{1}$, Toru Higuchi ${ }^{3}$, Atsushi Arakawa ${ }^{2}$ and Mitsue Saito
}

\begin{abstract}
Background: Human epidermal growth factor receptor 2 (HER2)-positive tumors are defined by protein overexpression (3+) or gene amplification using immunohistochemistry (IHC) or fluorescence in situ hybridization (FISH), respectively. HER2-positive tumors have historically included both $\mathrm{IHC}(3+)$ and $\mathrm{IHC}(2+$, equivocal)/FISH(+) tumors and received the same treatment. Differences in biology between these two tumor types, however, are poorly understood. Considering anti-HER2 drugs bind directly to HER2 protein on the cell surface, we hypothesized anti-HER2 therapies would be less effective in $\mathrm{HC}(2+) / F I S H(+)$ tumors than in $\mathrm{HC}(3+)$ tumors, leading to differences in patient outcomes.

Methods: A total of 447 patients with HER2-positive invasive carcinoma who underwent curative surgery were retrospectively investigated. HER2 status was assessed in surgical specimens, except in patients who received neoadjuvant chemotherapy, where biopsy specimens were employed.
\end{abstract}

Results: Age, tumor size, lymph node status and ER status were independent factors relating to disease-free-survival, but no difference was observed between $\mathrm{IHC}(3+)$ and $\mathrm{IHC}(2+) / \mathrm{FISH}(+)$ tumors. Kaplan-Meier analysis found patient outcomes did not differ, even after stratifying into those that did $(n=314)$, or did not $(n=129)$, receive chemotherapy with anti-HER2 drugs. In 134 patients who received NAC, pathological complete response rates in IHC(3+) and $\mathrm{IHC}(2+) / \mathrm{FISH}(+)$ tumors were $45 \%$ and $21 \%$, respectively. Survival after developing metastasis was significantly shorter in the $\mathrm{IHC}(2+) / \mathrm{FISH}(+)$ group.

Conclusions: The prognosis of patients with $\mathrm{IHC}(2+) / \mathrm{FISH}(+)$ tumors did not differ from $\mathrm{IHC}(3+)$ tumors. However, the significance of HER2 protein overexpression in relation to treatment response remains unclear and warrants further investigations.

Keywords: Breast cancer, HER2, Immunohistochemistry, In situ hybridization, Trastuzumab

\section{Introduction}

Human epidermal growth factor receptor 2 (HER2), a receptor tyrosine-protein kinase, is encoded by the HER2/neu gene in humans. Amplification or over-expression of this oncogene plays a crucial role in breast cancer

\footnotetext{
*Correspondence: horimoto@juntendo.ac.jp

${ }^{1}$ Department of Breast Oncology, Juntendo University School

of Medicine, 2-1-1 Hongo, Bunkyo-ku, 113-0033 Tokyo, Japan

Full list of author information is available at the end of the article
}

development and progression by inducing downstream pathways, such as PI3K/Akt [1]. Anti-HER2 drugs work by binding to HER2 expressed on the surface of cancer cells. HER2-positive breast cancers previously had poor prognosis [2,3], but the introduction of trastuzumab, a pioneer anti-HER2 drug, has dramatically improved patient outcomes [4].

Attention is needed, however, in the definition of HER2-positive tumors. HER2 protein expression and 
HER2/neu amplification are clinically assessed with immunohistochemistry (IHC) and fluorescence in situ hybridization (FISH), respectively. According to the American Society of Clinical Oncology and the College of American Pathologists (ASCO/CAP) guidelines, a HER2-positive tumor is defined as either $\mathrm{IHC}(3+)$ (i.e., overexpressed) or $\mathrm{FISH}(+)$ (i.e., amplified) [5]. In practice, however, most cases are first assessed with IHC, and only cases scored as $\mathrm{IHC}(2+)$, i.e., equivocal, are assessed with FISH for HER2/neu amplification. Generally, HER2 overexpressed $\mathrm{IHC}(3+)$ tumors are considered to have HER2/neu amplification, with a concordance rate of approximately $90 \%[6,7]$. In $\mathrm{IHC}(2+)$ tumors, FISH is positive in around $10-20 \%$ of cases [7-9].

While trastuzumab-based treatments have shown benefit in patients with $\mathrm{IHC}(3+)$ or $\mathrm{FISH}(+)$ tumors, the definition of HER2-positive tumors differed amongst clinical trials $[4,6,10-13]$. In clinical practice, both $\operatorname{IHC}(3+)$ and $\mathrm{IHC}(2+) / \mathrm{FISH}(+)$ tumors are treated as HER2-positive breast cancer, which is also the case for some new HER2targeted drugs, such as pertuzumab. Numerous clinical trials have shown both $\mathrm{IHC}(3+)$ and $\mathrm{IHC}(2+) / \mathrm{FISH}(+)$ tumors demonstrated significant benefit from additional trastuzumab, used either alone or in combination with chemotherapeutic drugs $[4,6,7,10-14]$.

Anti-HER2 drugs may be less effective in $\mathrm{IHC}(2+) /$ $\mathrm{FISH}(+)$ tumors due to less HER2 protein expressed on the cell surface. In a large randomized phase III clinical trial (N9831, $n=1,888$ ) investigating the benefit of additional trastuzumab to adjuvant chemotherapies, patients with IHC-negative and $\mathrm{FISH}(+)$ tumors showed no improvement in disease-free-survival with additional trastuzumab, while patients with $\mathrm{IHC}(3+) / \mathrm{FISH}(-)$ tumors demonstrated disease-free-survival comparable to those with $\mathrm{IHC}(3+) / \mathrm{FISH}(+)$ tumors, suggesting a key role of protein overexpression [13]. The differences in patient outcomes and efficacy with anti-HER2 therapies between $\mathrm{IHC}(3+)$ and $\mathrm{IHC}(2+) / \mathrm{FISH}(+)$ tumors, however, have not been well studied and are poorly understood.

Multi-gene panel tests have been recently introduced into clinical practice for patients with metastatic breast cancer. These tests evaluate gene status rather than protein expression in the tumor, and are being increasingly used to guide treatment decisions. Indeed, even if HER2 protein expression in the primary tumor is low, antiHER2 therapy may be offered if the tumor is determined to be HER2-positive by gene panel tests.

The aim of this study was to determine if the therapeutic effects of anti-HER2 therapies and patient outcomes differed between $\mathrm{IHC}(3+)$ and $\mathrm{IHC}(2+) / \mathrm{FISH}(+)$ tumors. We retrospectively investigated patients with HER2-positive invasive breast cancer treated at our hospital, focusing on the differences between patients with $\mathrm{IHC}(3+)$ and $\mathrm{IHC}(2+) / \mathrm{FISH}(+)$ tumors.

\section{Patients and methods}

\section{Patients}

A total of 447 patients with HER2-positive invasive carcinoma underwent curative surgery at our institution from 2010 to 2019. HER2 status was assessed from surgical specimens or, for patients who had received neoadjuvant chemotherapy (NAC) before surgery, biopsy specimens were assessed to avoid chemotherapy-related effects. Following surgery, standard adjuvant treatments were administered based on tumor characteristics. Details of adjuvant systemic treatments are shown in Additional file 1. Among the 318 patients who received chemotherapy, 171 (54\%) patients were given an anthracycline-based regimen; epirubicin plus cyclophosphamide (EC), followed by taxanes (paclitaxel or docetaxel). Another 129 (41\%) patients received EC only, while 18 (6\%) were given a taxane only. In the 328 patients who received anti-HER2 therapy, trastuzumab was used alone in 289 (88\%) patients, while pertuzumab was also used in a combination therapy in 38 (12\%) patients. The current retrospective study includes patients who did not receive systemic treatments for some other reasons, such as refusal by the patient, or where the indication for chemotherapy was not clear. This study was performed with approval from the ethics committee of Juntendo University Hospital (H19-0289), and all data were collected after obtaining informed consent from the patients. All data were anonymized before use.

\section{Pathologic assessment}

Pathologic examinations were carried out at Juntendo University Hospital by two experienced pathologists. Tumor grade was judged based on the modified BloomRichardson histologic grading system. For patients who received NAC, a pathological complete response (pCR) was defined as the disappearance of invasive nest in the primary breast tumor, i.e., without any lymph node evaluation. Estrogen receptor (ER) and progesterone receptor (PgR) statuses were assessed semi-quantitatively with $\mathrm{IHC}$, and reported as positive when $>1 \%$ of cancer cell nuclei showed staining. For the Ki67 labelling index, cells positive for nuclear Ki67 were evaluated semi-quantitatively within a selected hotspot microscopically under high magnification.

The criteria for HER2 assessment were revised slightly by the ASCO/CAP in 2018 [5]. However, this study used the pre-revision criteria $[15,16]$ since our cases were diagnosed before the 2018 revision. Employing rabbit monoclonal antibody (clone 4B5, Ventana), HER2 
protein expression was judged as 0 (negative, no staining observed, or membrane staining in $<10 \%$ of tumor cells), $1+$ (negative, faint focal membrane staining in $>10 \%$ of tumor cells), $2+$ (equivocal, weak to moderate staining of the cell membrane in $>10 \%$, or strong staining of the complete membrane in $\leq 10 \%$ of tumor cells), and $3+$ (positive, strong staining of the complete membrane in $>10 \%$ of tumor cells). Patients diagnosed between 2010 and 2012 inclusive, used a 30\% cut-off value for 3+, based on ASCO/CAP guidelines during that time [15]. Representative images of IHC are shown in Additional file 2. FISH was conducted using a PathVysion HER2 DNA Probe Kit (Abbott Japan, Tokyo, Japan). HER2/neu gene amplification was defined as being present when the FISH ratio was $>2.0$. In rare cases, some tumors switched from HER2-negative to HER2-positive on IHC following NAC treatment (e.g., IHC $1+$ to $3+$ ). Such cases were excluded from the current study.

\section{Statistical analysis}

Statistical analyses were performed using JMP 11.2.1 statistical software (SAS Institute Inc., Cary, NC). For comparisons of mean values, such as age, examinations of unpaired data were performed employing the twosided Student's $t$-test. As a test of independence, the Pearson's Chi-squared test was used. For evaluation of any independent prognostic effects of the variables, the Cox proportional hazard model was applied with a $95 \%$ confidence interval. For continuous variables, mean values were used as the threshold to distinguish between high and low groups. Mean values were 56 (age), $17 \mathrm{~mm}$ (pathological tumor size), and 48\% (Ki67 labelling index). The full-model analysis selected variables according to their clinical significance, specifically; age, pathological tumor size, lymph node involvement, tumor grade, ER and HER2 status, and administration of chemotherapy. Kaplan-Meier curves were produced and the log-rank test was applied for comparisons of survival between the two populations. A $P$-value $<0.05$ was considered statistically significant.

\section{Results}

\section{Characteristics of patients with HER2-positive tumors}

Clinicopathologic features of the 447 patients, including systemic treatments, are shown in Additional file 1. The numbers of $\mathrm{IHC}(3+)$ and $\mathrm{IHC}(2+) / \mathrm{FISH}(+)$ tumors were $398(89 \%)$ and 49 (11\%), respectively. Among all 447 patients, 134 received NAC. In total, 318 patients received adjuvant chemotherapies: 54\% received an anthracycline-based regimen followed by taxane, $41 \%$ received only an anthracycline-based regimen, and $6 \%$ received only taxane. HER2-targeted drug(s) were concurrently administered and continued for one year in total. In some NAC cases however, patients started trastuzumab after surgery, due to the drug having just been approved for NAC in Japan at that time (in 2010). Pertuzumab was simultaneously administered with trastuzumab in $12 \%$ of patients who received HER2-targeted drugs. Endocrine treatments were given to patients with hormone receptor (HR)-positive tumors according to menstrual status.

We further analyzed these data according to HER2 status (Table 1$)$. In the $\mathrm{IHC}(2+) / \mathrm{FISH}(+)$ group, significantly more ER and PgR tumors were observed $(P<0.001$ and $P=0.001$, respectively), while no differences found between other factors such as tumor grade and the administration of chemotherapy. Reflecting on HR status, adjuvant endocrine therapy was given to more patients with $\mathrm{IHC}(2+) / \mathrm{FISH}(+)$ tumors $(P=0.003)$.

\section{Clinicopathological factors relating to NAC}

In the 134 patients who received NAC, 57 patients obtained pCR. Clinicopathological features of the 134 patients stratified according to chemo-effect are shown in Table 2. The pCR group exhibited a higher Ki67 labelling index $(P=0.009)$. Significantly more patients who had received a combination of anthracycline and taxane as chemotherapy were observed in the $\mathrm{pCR}$ group $(P=0.019)$. No difference in the $\mathrm{pCR}$ rate was observed when stratified by ER status. pCR rates in $\mathrm{IHC}(3+)$ and $\mathrm{IHC}(2+) / \mathrm{FISH}(+)$ tumors were $45 \%$ (54 of 120 cases) and $21 \%$ ( 3 of 14 ), respectively, but there was no statistically significant difference $(P=0.091)$.

\section{Factors relating with patient outcomes}

During the mean observation period of 59 months (range, 1-137), 42 patients developed distant metastasis (9.4\% of the 447 cases). Fourteen patients (3.1\%) died due to breast cancer. Univariate analysis revealed pathological tumor size and lymph node involvement were associated with disease-free-survival (DFS; Table 3). With multivariate analysis, age, tumor size, lymph node status and ER were independent factors $(P=0.043$, $P<0.001, P<0.001$, and $P=0.012$, respectively). In other words, patients that were young, with tumors that were larger, had lymph node metastasis, and/or were ER-negative, had significantly shorter DFS. There was no difference between $\mathrm{IHC}(3+)$ and $\mathrm{IHC}(2+) /$ $\mathrm{FISH}(+)$ tumors.

Kaplan-Meier analysis was then used to assess differences in patient outcomes between $\mathrm{IHC}(3+)$ and $\mathrm{IHC}(2+) / \mathrm{FISH}(+)$ tumors according to systemic therapies. There was no difference in DFS or breast cancer-related overall survival (OS) between patients 


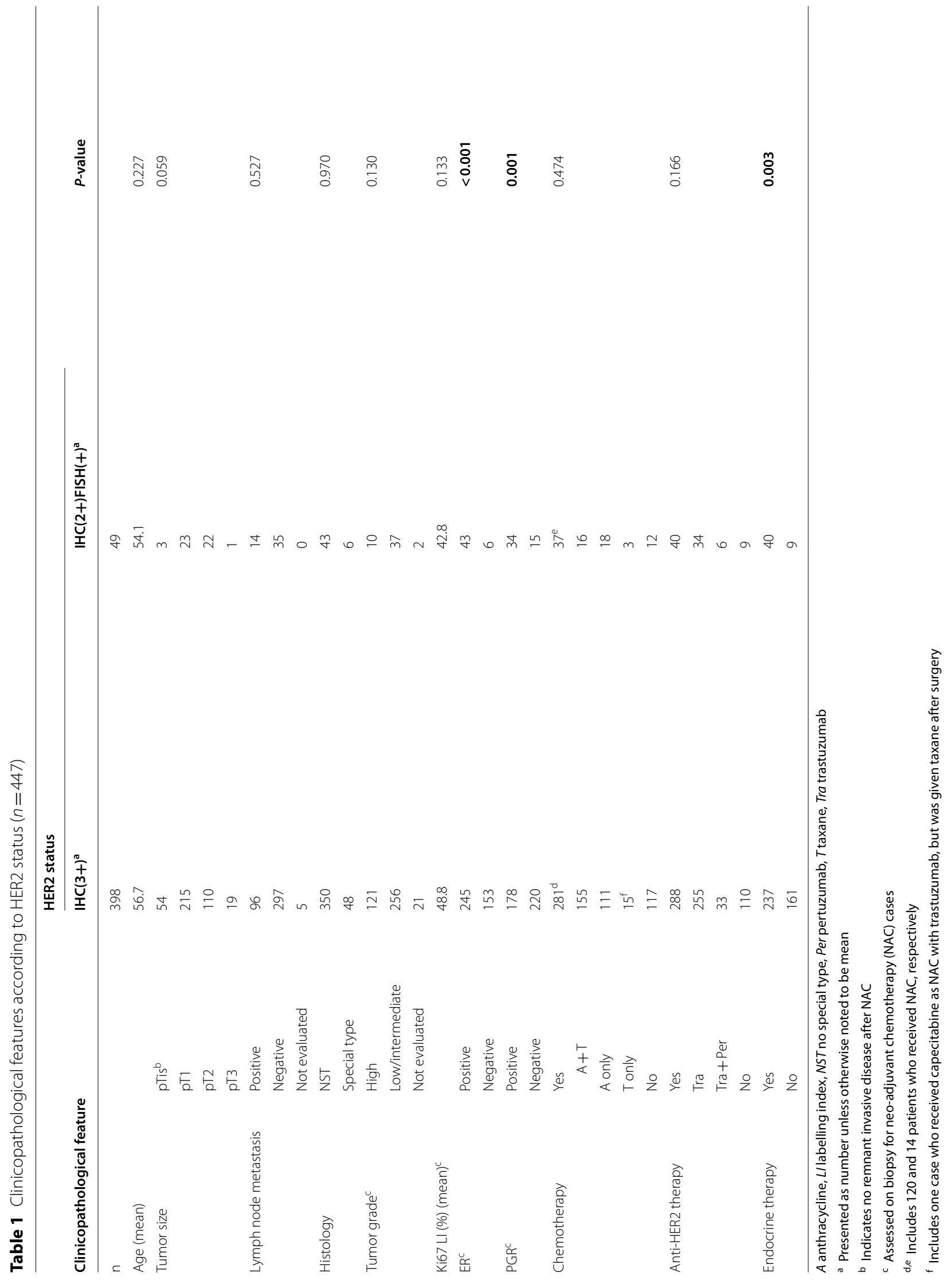


Table 2 Clinicopathological features of neo-adjuvant chemotherapy cases according to chemo-effect $(n=134)$

\begin{tabular}{|c|c|c|c|c|c|c|}
\hline \multirow[b]{2}{*}{ Variables } & & \multicolumn{2}{|l|}{$\mathrm{pCR}$} & \multicolumn{2}{|c|}{ non-pCR } & \multirow[t]{2}{*}{$P$-value } \\
\hline & & $\mathrm{n}^{\mathrm{a}}$ & $\%^{b}$ & $n^{a}$ & $\%^{\mathrm{b}}$ & \\
\hline$n$ & & 57 & & 77 & & \\
\hline Age (mean, range) & & 52.8 & $26-81$ & 51.9 & $26-79$ & 0.665 \\
\hline \multirow[t]{2}{*}{ Histology ${ }^{c}$} & NST & 53 & 93 & 76 & 99 & 0.084 \\
\hline & Special type & 4 & 7 & 1 & 1 & \\
\hline \multirow[t]{3}{*}{ Tumor grade ${ }^{c}$} & High & 16 & 28 & 24 & 31 & 0.980 \\
\hline & Low/intermediate & 35 & 61 & 52 & 68 & \\
\hline & Not evaluated & 6 & 11 & 1 & 1 & \\
\hline Ki67 LI (\%) (mean, range) & & 61.4 & $10-90$ & 49.7 & $5-95$ & 0.009 \\
\hline \multirow[t]{2}{*}{$E R^{c}$} & Positive & 33 & 58 & 46 & 60 & 0.830 \\
\hline & Negative & 24 & 42 & 31 & 40 & \\
\hline \multirow[t]{2}{*}{$\mathrm{PgR}^{c}$} & Positive & 18 & 32 & 31 & 40 & 0.302 \\
\hline & Negative & 39 & 68 & 46 & 60 & \\
\hline \multirow[t]{2}{*}{ HER2 ${ }^{C}$} & $3+$ & 54 & 95 & 66 & 86 & 0.091 \\
\hline & $2+\mathrm{FISH}+$ & 3 & 5 & 11 & 14 & \\
\hline \multirow[t]{4}{*}{ Chemotherapy $^{d}$} & $A+T$ & 56 & 98 & 63 & 82 & 0.019 \\
\hline & A only & 0 & 0 & 11 & 14 & \\
\hline & Tonly & 1 & 2 & 2 & 3 & \\
\hline & Others & 0 & 0 & $1^{e}$ & 1 & \\
\hline \multirow[t]{3}{*}{ Anti-HER2 therapy ${ }^{d}$} & Tra only & 38 & 67 & 45 & 58 & 0.076 \\
\hline & Tra + Per & 8 & 14 & 5 & 6 & \\
\hline & None & 11 & 19 & 27 & 35 & \\
\hline
\end{tabular}

$p C R$ pathological complete response, NST no special type, LI labelling index, $A$ anthracycline, $T$ taxane, Tra trastuzumab, Per pertuzumab

a Presented as $n$ unless otherwise noted to be mean

b Presented as \% unless otherwise noted to be range

c Assessed on biopsy for neo-adjuvant chemotherapy (NAC) cases

d For NAC

e Capecitabe was given with trastuzumab

with $\mathrm{IHC}(3+)$ and $\mathrm{IHC}(2+) / \mathrm{FISH}(+)$ tumors when evaluating all participants $(n=447$; Fig. $1 \mathrm{~A}$ and B). Similarly, there was no difference in DFS or breast cancer-related OS between patients with $\operatorname{IHC}(3+)$ and $\mathrm{IHC}(2+) / \mathrm{FISH}(+)$ tumors in patients who received a combination of chemotherapeutic and anti-HER2 drugs as standard adjuvant treatment, regardless of whether it was administered pre/postoperatively ( $n=314$; Fig. $1 \mathrm{C}$ and D), or patients who did not receive any chemotherapy $(n=129$; Fig. 1E F). The four patients who received adjuvant chemotherapy but not anti-HER2 drugs for some reason were excluded from the analysis shown in Fig. $1 \mathrm{C}$ and D. A subset analysis compared DFS in the 133 patients that received NAC, and similarly found no difference in DFS between patients with $\mathrm{IHC}(3+)$ and $\mathrm{IHC}(2+) / \mathrm{FISH}(+)$ tumors $(P=0.821$; Additional file 3).
Patient outcomes were separately analyzed after stratifying by HR status (Additional file 4). The main results did not change, in that there was no significant difference in DFS or OS between $\mathrm{IHC}(2+) / \mathrm{FISH}(+)$ and $3+$ tumors in all patients or those treated with adjuvant chemotherapy after separating HR-positive and HR-negative tumors. However, in patients with HR-negative tumors, $\mathrm{IHC}(2+) / \mathrm{FISH}(+)$ tumors had significantly shorter OS than $3+$ tumors. The small sample of the IHC(2+)/FISH $(+)$ group $(n=4)$ however, means the significance of this result is inconclusive.

Finally, survival after developing metastasis was analyzed in 47 patients who developed distant metastasis (Fig. 2). The $\mathrm{IHC}(3+)$ group $(n=37)$ had a mean survival of 32 months (range, $0-1184$ ), while the $\mathrm{IHC}(2+) /$ $\mathrm{FISH}(+)$ group $(n=5)$ had significantly shorter survival (mean, 9 months; range, 3-22; $P=0.018$ ), although the number of patients in this group was obviously small. 
Table 3 Clinicopathological features in relation to disease-free-survival $(n=447)$

\begin{tabular}{|c|c|c|c|c|c|c|}
\hline \multirow[b]{2}{*}{ Variables } & \multirow[b]{2}{*}{ HR } & \multirow{2}{*}{$\begin{array}{l}\text { Univariate } \\
95 \% \mathrm{Cl}\end{array}$} & \multirow[b]{2}{*}{$P$-value } & \multirow[b]{2}{*}{ HR } & \multicolumn{2}{|c|}{ Multivariate } \\
\hline & & & & & $95 \% \mathrm{Cl}$ & $P$-value \\
\hline Age (> 56 vs. $\leq 56)$ & 0.67 & $0.45-1.24$ & 0.200 & 0.51 & $0.25-0.98$ & 0.043 \\
\hline $\begin{array}{l}\text { Tumor size } \\
(>17 \mathrm{~mm} \\
\text { vs. } \leq 17 \mathrm{~mm})\end{array}$ & 3.72 & $1.95-7.56$ & $<0.001$ & 3.24 & $1.64-6.76$ & $<0.001$ \\
\hline $\begin{array}{l}\text { Lymph node } \\
\text { metastasis (posi- } \\
\text { tive vs. negative) }\end{array}$ & 4.93 & $2.68-9.29$ & $<0.001$ & 4.24 & $2.23-8.24$ & $<0.001$ \\
\hline $\begin{array}{l}\text { Histology (NST vs. } \\
\text { special type) }\end{array}$ & 0.98 & $0.42-2.86$ & 0.973 & & & \\
\hline $\begin{array}{l}\text { Tumor grade } \\
\text { (high vs. low/ } \\
\text { intermediate) }\end{array}$ & 0.89 & $0.43-1.73$ & 0.740 & 0.88 & $0.41-1.75$ & 0.725 \\
\hline $\begin{array}{l}\text { Ki67 LI (>48\% } \\
\text { Vs. } \leq 48 \%)\end{array}$ & 0.91 & $0.46-1.81$ & 0.790 & & & \\
\hline $\begin{array}{l}\text { ER (positive vs. } \\
\text { negative) }\end{array}$ & 0.58 & $0.32-1.07$ & 0.082 & 0.43 & $0.22-0.83$ & 0.012 \\
\hline $\begin{array}{l}\text { PgR (positive vs. } \\
\text { negative) }\end{array}$ & 0.84 & $0.45-1.55$ & 0.582 & & & \\
\hline $\begin{array}{l}\text { HER2 } \\
(2+\mathrm{FISH}+\text { vs. } 3+)\end{array}$ & 1.08 & $0.37-2.52$ & 0.866 & 1.10 & $0.36-2.75$ & 0.855 \\
\hline $\begin{array}{l}\text { Administration } \\
\text { of chemotherapy } \\
\text { (yes vs. no) }\end{array}$ & 0.92 & $0.48-1.88$ & 0.814 & 0.57 & $0.29-1.21$ & 0.139 \\
\hline $\begin{array}{l}\text { Administration of } \\
\text { anti-HER2 therapy } \\
\text { (yes vs. no) }\end{array}$ & 1.06 & $0.54-2.27$ & 0.873 & & & \\
\hline
\end{tabular}

NST no special type, L/ labelling index, $H R$ hazard ratio, $\mathrm{Cl}$ confidence interval

\section{Discussion}

In this study, we found patient outcomes did not differ between breast cancer patients with $\mathrm{IHC}(3+)$ and $\mathrm{IHC}(2+) / \mathrm{FISH}(+)$ tumors. Even after stratifying patients into those that had or had not received adjuvant chemotherapy with anti-HER2 drugs, there was no difference in patient outcomes. To the best of our knowledge, there has been no other report comparing patient outcomes with these two tumors. To determine whether $\mathrm{IHC}(3+)$ and $\mathrm{IHC}(2+) / \mathrm{FISH}(+)$ tumors differ in their intrinsic malignancy, it is necessary to compare patients who did not receive chemotherapy. However, our cohort was retrospectively collected and the application of chemotherapy was not randomized. Moreover, the sample size of the non-chemotherapy group was relatively small. Hence, we were not able to adequately examine this point. It is no longer ethical to employ an arm without anti-HER2 agents in prospective clinical trials. As such, more retrospective observational studies such as the present study need to be collated.

As to the effectiveness of anti-HER2 therapies, in the NAC setting, pCR rates were lower in $\mathrm{IHC}(2+) /$ $\mathrm{FISH}(+)$ tumors compared with $\mathrm{IHC}(3+)$, although the difference did not reach statistical significance. Small sample numbers might have affected the statistical analysis. Meanwhile, patients with $\mathrm{IHC}(2+) / \mathrm{FISH}(+)$ tumors showed significantly shorter survival after developing distant metastases. Considering anti-HER2 therapies are given to patients with both $\mathrm{IHC}(3+)$ and $\mathrm{IHC}(2+) /$ $\mathrm{FISH}(+)$ tumors, we cannot exclude the possibility that $\mathrm{IHC}(2+) / \mathrm{FISH}(+)$ tumors do not respond well to antiHER2 therapies. In the N9831 clinical trial, patients with

(See figure on next page.)

Fig. 1 Patient outcomes stratified by HER2 status. A-B Kaplan-Meier analyses indicate disease-free-survival (DFS) (A) and breast cancer-related overall survival (OS) (B) according to HER2 status in all 447 patients. Green and red lines indicate patients with IHC(3+) and IHC(2+)/FISH(+) tumors, respectively. C-D DFS (C) and OS (D) in the 314 patients who received adjuvant chemotherapies in combination with anti-HER2 drugs. E-F DFS (E) and OS (F) in the 129 patients who did not receive any chemotherapy 


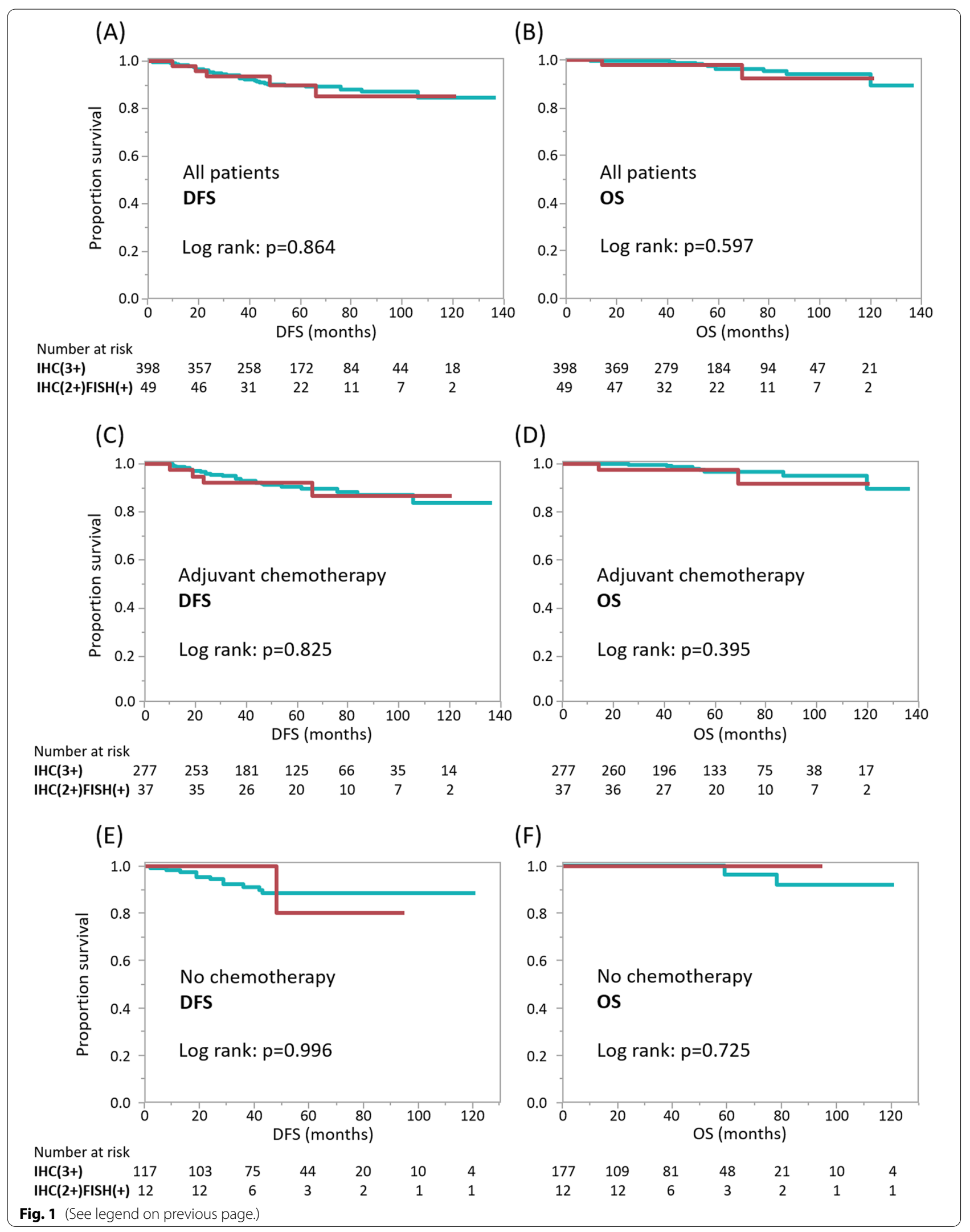




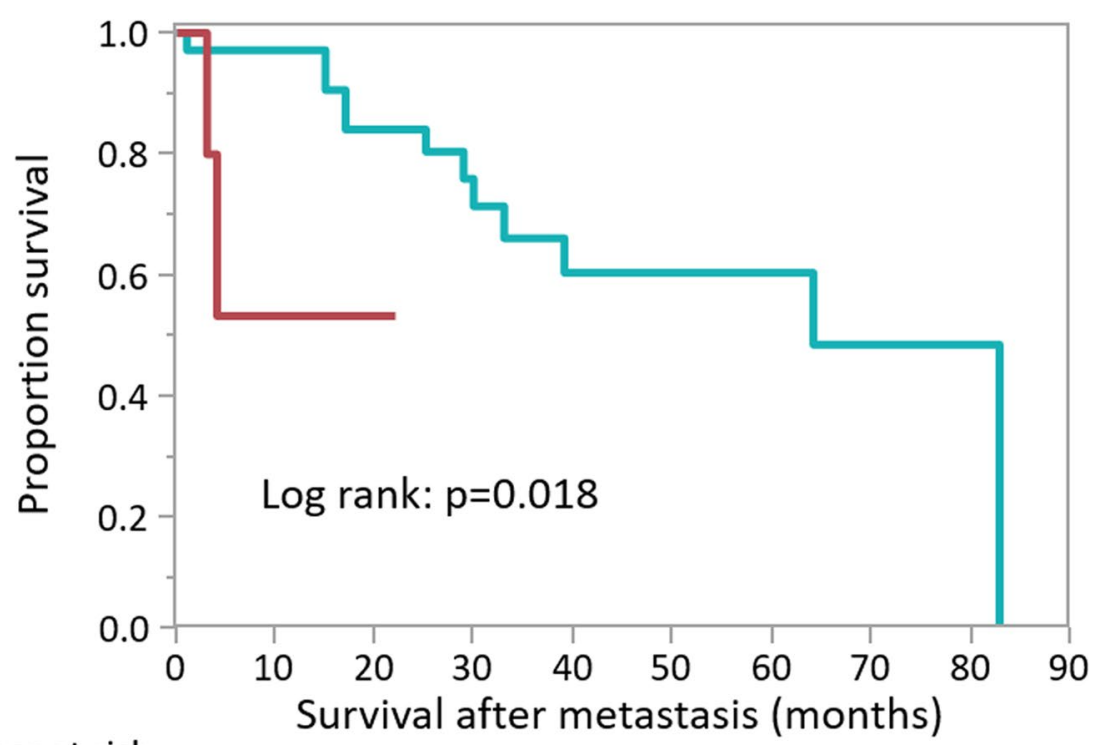

Number at risk

$\begin{array}{lccccccccc}\mathrm{IHC}(3+) & 37 & 31 & 23 & 17 & 11 & 11 & 7 & 5 & 3 \\ \mathrm{IHC}(2+) \mathrm{FISH}(+) & 5 & 3 & 2 & 0 & 0 & 0 & 0 & 0 & 0\end{array}$

Fig. 2 Survival after developing distant metastasis, stratified by HER2 status $(n=42)$. Kaplan-Meier analyses indicate survival after developing distant metastasis. Green and red lines indicate patients with $\mathrm{IHC}(3+)$ and $\mathrm{IHC}(2+) / \mathrm{FISH}(+)$ tumors, respectively

IHC-negative and $\mathrm{FISH}(+)$ tumors had no additional benefit, in terms of prolonging DFS, with receiving trastuzumab with adjuvant chemotherapies [13]. The importance of HER2 protein overexpression merits further investigation. It would be relatively easy to conduct an additional analysis in recent clinical trials that include a variety of anti-HER2 drugs, to evaluate treatment effectiveness in $\mathrm{IHC}(3+)$ and $\mathrm{IHC}(2+) / \mathrm{FISH}(+)$ tumors.

The $\mathrm{IHC}(2+) / \mathrm{FISH}(+)$ group included significantly more HR-positive tumors. However, this phenomenon is probably caused by selection bias rather than biological difference, as ER-positive tumors were predominant among those in which FISH was examined (data not shown). ER can regulate and activate HER2 signaling $[9,17,18]$, thus crosstalk signaling may influence HER2 protein expression in FISH + tumors. However, to test this hypothesis, all FISH + tumors should be examined regardless of IHC results. We could not investigate this issue in the current study as FISH was conducted only in $\mathrm{IHC}(2+)$ tumors. Nevertheless, the fact that pCR rate did not differ in relation to ER status indicates chemotherapy with anti-HER2 treatment is effective in ER and HER2positive tumors, as well as HER2 type (HR-negative and HER2-positive) tumors. Meanwhile, patients with ERpositive tumors had significantly longer DFS. Adjuvant endocrine treatments should, of course, contribute to these patients' prognoses.
The major limitation of our study was that it was a retrospective observational study, thus systemic treatments, such as chemotherapy and anti-HER2 drugs, were not uniform. Further analysis with a larger sample size is required, especially to further examine patient outcomes of $\mathrm{IHC}(2+) / \mathrm{FISH}(+)$ and HR-negative tumors, and to compare the effects of treatment after recurrence. In addition, while FISH was only performed in $\mathrm{IHC}(2+)$ tumors, it can be assumed that some $\mathrm{IHC}(0 / 1+)$ tumors are also $\mathrm{FISH}(+)$ [19]. The biological behavior of FISH(+) tumors with none/little HER2 protein should be thoroughly assessed in the near future, particularly given that a large number of clinical trials of novel HER2 proteinanchored drugs are currently ongoing.

\section{Conclusions}

In summary, our data indicate that prognosis of patients with $\mathrm{IHC}(2+) / \mathrm{FISH}(+)$ tumors do not differ from those with $\mathrm{IHC}(3+)$ tumors. The significance of the levels of HER2 protein overexpression in relation to response to anti-HER2 therapies remains unclear. We believe that further investigation is vital to enable provide patients with more personalized treatments.

\section{Abbreviations}

ASCO/CAP: American Society of Clinical Oncology and the College of American Pathologists; DFS: disease-free-survival; EC: epirubicin plus cyclophosphamide; ER: estrogen receptor; FISH: fluorescence in situ hybridization; HER2: 
Human epidermal growth factor receptor 2; HR: hormone receptor; IHC: immunohistochemistry; NAC: neo-adjuvant chemotherapy; OS: overall survival; pCR: pathological complete response; PgR: progesterone receptor.

\section{Supplementary Information}

The online version contains supplementary material available at https://doi. org/10.1186/s12885-022-09351-4.

Additional file 1. Clinicopathological features of HER2-positive patients $(n=447)$.

Additional file 2. Representative images of HER2 IHC $(0,1+, 2+$, and $3+)$ are shown.

Additional file 3. DFS in NAC cases according to HER2 status. KaplanMeier analysis indicates disease-free-survival (DFS) according to HER2 status in 133 patients who received NAC containing anti-HER2 drugs. Green and red lines indicate patients with $\mathrm{IHC}(3+)$ and $\mathrm{IHC}(2+) / \mathrm{FISH}(+)$ tumors, respectively.

Additional file 4. Patient outcomes stratified by hormone receptor and HER2 status. A-B: DFS (A) and OS (B) are separately analyzed according to hormone receptor (HR) status in all 447 patients. Green and red lines indicate patients with $\mathrm{IHC}(3+)$ and $\mathrm{IHC}(2+) / F \mathrm{FSH}(+)$ tumors, respectively. C-D: DFS (C) and OS (D) in the 314 patients who received adjuvant chemotherapies in combination with anti-HER2 drugs. E-F: DFS (E) and OS (F) in the 129 patients who did not receive any chemotherapy.

\section{Acknowledgements}

The authors sincerely appreciate Clear Science Pty Ltd for language editing.

\section{Authors' contributions}

$\mathrm{YH}, \mathrm{Yl}$ and $\mathrm{TH}$ designed this study. $\mathrm{YH}$ and AA performed pathological assessment. $Y H, Y$, and $Y U$ collected clinical data. $Y H$ conducted data analysis and statistics. YH drafted the original manuscript and MS substantively revised it. All authors have read and approved the manuscript.

\section{Funding}

This study was supported by the Japan Society for the Promotion of Science Grant-in-Aid for Young Scientists (Grant No. JP17K16517), to support data analysis.

\section{Availability of data and materials}

The datasets analyzed during the current study are available from the corresponding author on reasonable request.

\section{Declarations}

\section{Ethics approval and consent to participate}

All procedures performed in studies involving human participants were in accordance with the ethical standards of the ethics committee of Juntendo University Hospital (no: H19-0289) and with the 1964 Helsinki declaration and its later amendments or comparable ethical standards. Written informed consent was obtained from all individual participants included in the study.

\section{Consent for publication}

Not applicable.

\section{Competing interests}

The authors have no conflict of interest to declare.

\section{Author details}

${ }^{1}$ Department of Breast Oncology, Juntendo University School of Medicine, 2-1-1 Hongo, Bunkyo-ku, 113-0033 Tokyo, Japan. ${ }^{2}$ Department of Human Pathology, Juntendo University School of Medicine, 2-1-1 Hongo, Bunkyo-ku, 113-0033 Tokyo, Japan. ${ }^{3}$ Department of Breast Oncology, Japanese Red Cross Saitama Hospital, 1-5 Shintoshin, Chuo-ku, 330-8553 Saitama, Japan.
Received: 22 August 2021 Accepted: 28 February 2022

Published online: 05 March 2022

\section{References}

1. Burstein $\mathrm{HJ}$. The distinctive nature of HER2-positive breast cancers. N Engl J Med. 2005;353:1652-4.

2. Slamon DJ, Clark GM, Wong SG, Levin WJ, Ullrich A, McGuire WL. Human breast cancer: correlation of relapse and survival with amplification of the HER-2/neu oncogene. Science. 1987;235:177-82.

3. Seshadri R, Firgaira FA, Horsfall DJ, McCaul K, Setlur V, Kitchen P. Clinical significance of HER-2/neu oncogene amplification in primary breast cancer. The South Australian Breast Cancer Study Group. J Clin Oncol. 1993;11:1936-42.

4. Smith I, Procter M, Gelber RD, Guillaume S, Feyereislova A, Dowsett M, Goldhirsch A, Untch M, Mariani G, Baselga J, Kaufmann M, Cameron D, Bell R, Bergh J, Coleman R, Wardley A, Harbeck N, Lopez RI, Mallmann P, Gelmon K, Wilcken N, Wist E, Sánchez Rovira P, Piccart-Gebhart MJ. 2-year follow-up of trastuzumab after adjuvant chemotherapy in HER2-positive breast cancer: a randomised controlled trial. Lancet. 2007;369:29-36.

5. Wolff AC, Hammond MEH, Allison KH, Harvey BE, Mangu PB, Bartlett JMS, Bilous M, Ellis IO, Fitzgibbons P, Hanna W, Jenkins RB, Press MF, Spears PA, Vance GH, Viale G, McShane LM, Dowsett M. Human Epidermal Growth Factor Receptor 2 Testing in Breast Cancer: American Society of Clinical Oncology/College of American Pathologists Clinical Practice Guideline Focused Update. J Clin Oncol. 2018;36:2105-22.

6. Vogel CL, Cobleigh MA, Tripathy D, Gutheil JC, Harris LN, Fehrenbacher L, Slamon DJ, Murphy M, Novotny WF, Burchmore M, Shak S, Stewart SJ, Press M. Efficacy and safety of trastuzumab as a single agent in first-line treatment of HER2-overexpressing metastatic breast cancer. J Clin Oncol. 2002;20:719-26.

7. Baselga J. Herceptin alone or in combination with chemotherapy in the treatment of HER2-positive metastatic breast cancer: pivotal trials. Oncology. 2001;61(Suppl 2):14-21.

8. Dybdal N, Leiberman G, Anderson S, McCune B, Bajamonde A, Cohen RL, Mass RD, Sanders C, Press MF. Determination of HER2 gene amplification by fluorescence in situ hybridization and concordance with the clinical trials immunohistochemical assay in women with metastatic breast cancer evaluated for treatment with trastuzumab. Breast Cancer Res Treat. 2005;93:3-11.

9. Horimoto Y, Terao T, Tsutsumi Y, Tanabe M, Mogushi K, Hlaing MT, Sasaki R, Saeki H, Okazaki M, Sonoue H, Arakawa A, Saito M. Estrogen Receptorpositive Ductal Carcinoma In Situ Frequently Overexpresses HER2 Protein Without Gene Amplification. Am J Surg Pathol. 2019;43:1221-8.

10. Cobleigh MA, Vogel CL, Tripathy D, Robert NJ, Scholl S, Fehrenbacher L, Wolter JM, Paton V, Shak S, Lieberman G, Slamon DJ. Multinational study of the efficacy and safety of humanized anti-HER2 monoclonal antibody in women who have HER2-overexpressing metastatic breast cancer that has progressed after chemotherapy for metastatic disease. J Clin Oncol. 1999;17:2639-48.

11. Slamon DJ, Leyland-Jones B, Shak S, Fuchs H, Paton V, Bajamonde A, Fleming T, Eiermann W, Wolter J, Pegram M, Baselga J, Norton L. Use of chemotherapy plus a monoclonal antibody against HER2 for metastatic breast cancer that overexpresses HER2. N Engl J Med. 2001;344:783-92.

12. Gasparini G, Gion M, Mariani L, Papaldo P, Crivellari D, Filippelli G, Morabito A, Silingardi V, Torino F, Spada A, Zancan M, De Sio L, Caputo A, Cognetti F, Lambiase A, Amadori D. Randomized Phase II Trial of weekly paclitaxel alone versus trastuzumab plus weekly paclitaxel as first-line therapy of patients with Her-2 positive advanced breast cancer. Breast Cancer Res Treat. 2007;101:355-65.

13. Perez EA, Reinholz MM, Hillman DW, Tenner KS, Schroeder MJ, Davidson NE, Martino S, Sledge GW, Harris LN, Gralow JR, Dueck AC, Ketterling RP, Ingle JN, Lingle WL, Kaufman PA, Visscher DW, Jenkins RB. HER2 and chromosome 17 effect on patient outcome in the N9831 adjuvant trastuzumab trial. J Clin Oncol. 2010;28:4307-15.

14. Fehrenbacher $L$, Cecchini RS, Geyer CE Jr, Rastogi P, Costantino JP, Atkins JN, Crown JP, Polikoff J, Boileau JF, Provencher L, Stokoe C, Moore TD, Robidoux A, Flynn PJ, Borges VF, Albain KS, Swain SM, Paik S, Mamounas EP, Wolmark N. NSABP B-47/NRG Oncology Phase III Randomized Trial Comparing Adjuvant Chemotherapy With or Without Trastuzumab in 
High-Risk Invasive Breast Cancer Negative for HER2 by FISH and With IHC $1+$ or 2. J Clin Oncol. 2020;38:444-53.

15. Wolff AC, Hammond MEH, Schwartz JN, Hagerty KL, Allred DC, Cote RJ, Dowsett M, Fitzgibbons PL, Hanna WM, Langer A, McShane LM, Paik S, Pegram MD, Perez EA, Press MF, Rhodes A, Sturgeon C, Taube SE, Tubbs R, Vance GH, Vijver M, Wheeler TM, Hayes DF. American Society of Clinical Oncology/College of American Pathologists Guideline Recommendations for Human Epidermal Growth Factor Receptor 2 Testing in Breast Cancer. J Clin Oncol. 2007:25:118-45.

16. Wolff AC, Hammond ME, Hicks DG, Dowsett M, MCShane LM, Allison KH, Allred DC, Bartlett JM, Bilous M, Fitzgibbons P, Hanna W, Jenkins RB, Mangu PB, Paik S, Perez EA, Press MF, Spears PA, Vance GH, Viale G, Hayes DF. Recommendations for human epidermal growth factor receptor 2 testing in breast cancer: American Society of Clinical Oncology/College of American Pathologists clinical practice guideline update. J Clin Oncol. 2013;31:3997-4013.

17. Hurtado A, Holmes KA, Geistlinger TR, Hutcheson IR, Nicholson RI, Brown M, Jiang J, Howat WJ, Ali S, Carroll JS. Regulation of ERBB2 by oestrogen receptor-PAX2 determines response to tamoxifen. Nature. 2008:456:663-6.

18. Jin K, Park S, Teo WW, Korangath P, Cho SS, Yoshida T, Győrffy B, Goswami CP, Nakshatri H, Cruz L-A, Zhou W, Ji H, Su Y, Ekram M, Wu Z, Zhu T, Polyak K, Sukumar S. HOXB7 Is an ERa Cofactor in the Activation of HER2 and Multiple ERTarget Genes Leading to Endocrine Resistance. Cancer Discov. 2015;5:944-59.

19. Higuchi T, Arisawa F, Hayashi Y, Manabe I, Suekuni K, Adachi A, Saito T. 373 Poster - Evaluation of FISH of ER-positive breast cancer with low-HER2 expression could improve their survival. Eur J Cancer. 2020;138:95.

\section{Publisher's Note}

Springer Nature remains neutral with regard to jurisdictional claims in published maps and institutional affiliations.

- fast, convenient online submission

- thorough peer review by experienced researchers in your field

- rapid publication on acceptance

- support for research data, including large and complex data types

- gold Open Access which fosters wider collaboration and increased citations

- maximum visibility for your research: over $100 \mathrm{M}$ website views per year

At BMC, research is always in progress.

Learn more biomedcentral.com/submissions 